\title{
A Research on Teaching Reform of "Embedded System" Based on CDIO Engineering Education Mode
}

\author{
LUO Yong \\ School of Electrical \& Information Engineering, Jinan University, Zhuhai, China
}

Keywords: Embedded System, CDIO, Teaching Reform, Talent Training.

\begin{abstract}
In view of the problems existing in the embedded system education in colleges and universities, in order to cultivate the compound embedded talents who meet the needs of the enterprise, based on the CDIO engineering education model, analyze the characteristics of "embedded system" curriculum, take the project development practice as the leading thought, discuss the curriculum system, teaching material construction, Teaching method reform. Through the project-driven teaching method, the students ' ability of engineering practice can be comprehensively upgraded, and the engineering development ability of embedded products can be achieved to meet the needs of innovative and compound talents.
\end{abstract}

\section{Introduction}

The CDIO Engineering education model is the latest achievement of international engineering education Reform. In 2010, its founder, Edward Crawley, was awarded the "Gordon Award" of the American Academy of Engineering, which was hailed as "the Nobel Prize for Engineering". The CDIO Engineering education model is a new type of educational model developed by four engineering schools in 2000 by MIT, Sweden and so on, which represents the development trend of contemporary higher engineering education [1]. The urgent task of higher engineering education in our country is to train Chinese engineers in line with the international standards as soon as possible, however, there are some problems in the educational practice of Chinese engineering, such as emphasizing theory light practice, stressing individual academic ability, and neglecting teamwork spirit, valuing knowledge learning and ignoring pioneering and innovating cultivation.

With the wide application of embedded technology, the market has a growing demand for professionals who are skilled in the embedded technology [2]. In this context, the embedded system curriculum has been favored by many universities. The course is a combination of theoretical and practical courses, with special emphasis on the cultivation of students' practical abilities, so the CDIO Engineering education model provides a new educational thought and method for embedded system curriculum. It takes the project the conception, the design, the implementation, the Operation life cycle as the carrier lets the student take the active way to study in the practice, thus comprehensively promotes the student's comprehensive quality and the innovation Spirit [3], satisfies the society to the Innovation Advanced engineering technical personnel the demand.

As an emerging curriculum, "Embedded System" curriculum system, textbook construction, teaching methods, teaching content (including hardware platform and software platform) selection, experimental teaching and practice links organization is still at the beginning of construction [4]. How to apply advanced CDIO engineering education idea to the course construction of "embedded system" is a problem worth discussing.

\section{Curriculum Features of "Embedded System"}

According to the IEEE definition, an embedded system is a device for controlling, monitoring, or assisting a device to run. The main features are the combination of software and hardware, and application-oriented; its three basic elements are embeddedness, specificity and computer system [4]. 
The development of embedded system product requires not only the designer to master the comprehensive theory knowledge but also the strong practical ability. Embedded system is a comprehensive, knowledge-covered curriculum, not only involves electronic technology, computer principles and other hardware knowledge, but also involves operating systems, applications and other software knowledge. The development process of embedded system needs the cooperation of assembler language, $\mathrm{C}, \mathrm{C}++$, Linux, ADS, KEIL MDK and so on, its process is extremely complex and tedious. It is difficult to achieve the expected teaching effect if we rely too much on classroom explanation and experiment teaching in the course, which is not conducive to fully cultivating students ' practical ability and stimulating their creative potential.

\section{The Current Situation and Main Problems of "Embedded System" Teaching}

Compared with other engineering courses, the "Embedded Systems" course has the following two salient features: a comprehensive discipline, and a strong curriculum. Traditional teaching cannot meet the requirements of different professional students for learning in embedded systems. The teaching results are also not satisfactory. There are mainly the following reasons:

1. The traditional curriculum organization structure takes the subject knowledge as the center, emphasizes the theory study, lacks the solution actual question ability training;

2. The lack of classical textbooks, the current embedded system of textbooks generally have a strong theoretical and operational shortcomings, at the same time, because of the wide range of embedded microprocessors, so that the reform of embedded system textbooks become more difficult;

3. Experimental teaching: There are more confirmatory experiments, less comprehensive development experiments, fewer experiments to cultivate students ' ability to innovate independently, and less experimental content reflecting the most advanced technology in the field;

4. Lack of cost-effective and practical embedded system teaching platform: Most colleges and universities currently use the Teaching experiment box provided by enterprises, not only the higher cost, but also greatly limits the development of students ' ability to develop and design;

5. The experimental equipment updates slow in some colleges and universities, and because of the rigid management system, resulting in students' exploratory learning time is too limited.

\section{Teaching Reform of "Embedded System" Based on CDIO Engineering Education Model}

In view of the problems existing in embedded system education in colleges and universities, the author's teaching team has made some attempts to cultivate the compound embedded talents who meet the needs of enterprises.

\subsection{Constructing CDIO Mode Course Teaching System}

According to the thought of CDIO Engineering education mode, the teaching system of embedded system is constructed as shown in Fig. 1, its content not only involves the knowledge of the most basic hardware and software, but also covers the integrated design of embedded system and the training of actual project, and forms the complete embedded system knowledge system coherently.

\subsection{Use the mainstream and easy to practice teaching experiment platform}

In order to adapt the software and hardware platform to the students ' learning needs, the paper makes a comprehensive analysis and comparison of the mainstream experimental platform in the market, and finally establishes the following products:

1. Select the STM32F103 Development Board as the main hardware experimental platform. The main reason is the STM32F103 series chip uses the CORTEX-M3 kernel, easy to learn and use, is widely used in Low-cost and low-power embedded terminal products;

2. Choose RealView MDK as an embedded software development environment, MDK-ARM integrates the industry's leading technology: including integrated development environment $\mathrm{uVision} 4$ 
and RealView compiler RVCT, support automatic configuration boot code, integrated Flash burn write module, powerful simulation equipment simulation, performance analysis and other functions. Performance can be increased by more than $20 \%$ compared to the Ads, RealView compiler.

3. Select $\mu \mathrm{C} / \mathrm{OS}-\mathrm{II}$ as the main embedded operating system used in teaching. $\mu \mathrm{C} / \mathrm{OS}$-II operating system code short, easy to read and understand. At the same time, the system includes functions such as real-time kernel, task management, and communication between tasks. Can meet the majority of students grasp the embedded operating system principles, multi-task programming methods, synchronization between tasks and communication and other learning needs.

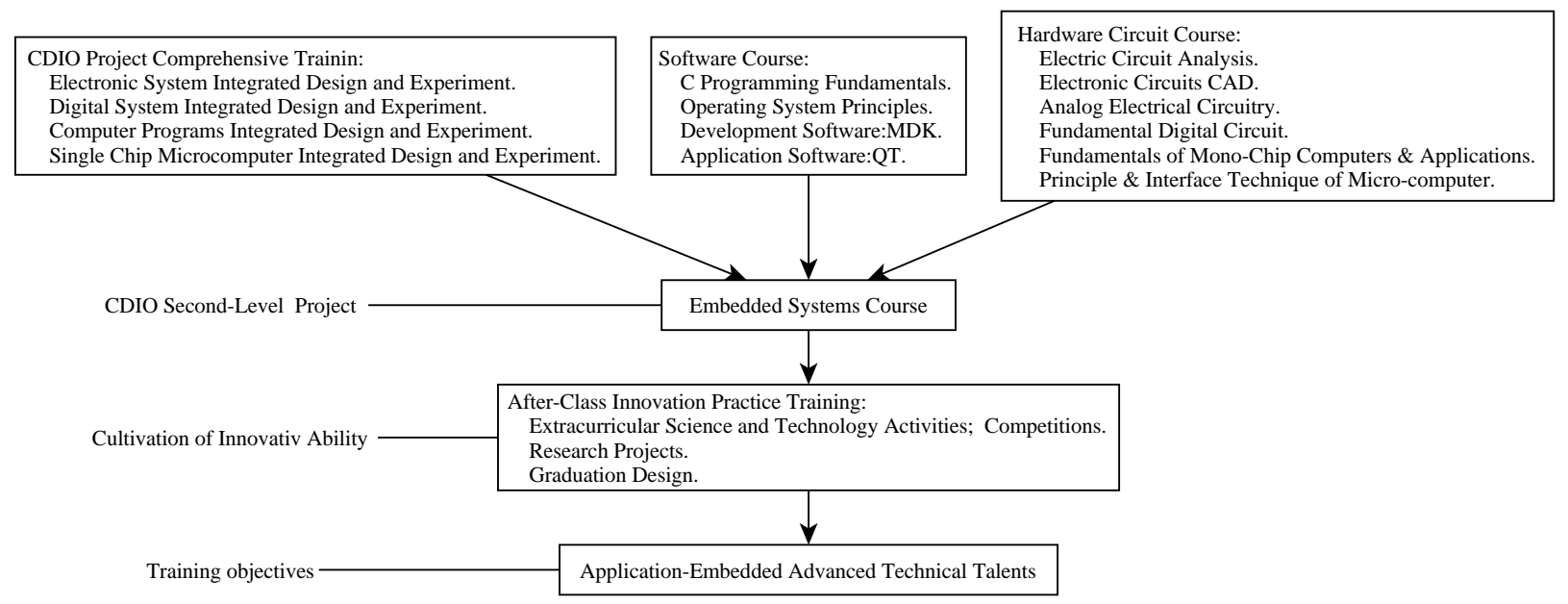

Fig. 1 CDIO Embedded System Course Teaching System

\subsection{Exploration and Attempt of Nonstandard Teaching Materials}

At present, the number of textbooks on embedded system is very large, and the structure is similar. This course uses the STM32F103 Experimental Development Board, which has a detailed and complete documentation and is equipped with an Easy-to-understand video tutorial. Therefore, in the classroom teaching, the teaching team did not give the students to assign textbooks, only recommended a number of reference materials, students are free to choose, while encouraging students to independently on the network to search for information, so that students start to establish independent search for relevant information practice.

\subsection{Distribute class hours appropriately}

Embedded system is a highly practical course, teaching team will be part of theoretical knowledge in the practice of teaching to explain, so that teaching has a higher efficiency. Therefore, we try to improve the proportion of teaching hours, the theory of education accounted for only about $1 / 8$ of the total hours, mainly to teach the most basic knowledge and basic principles; the rest of the class schedule for the engineering practice development course, the project development and related theories through the project case design way to explain.

\subsection{Implementing hierarchical teaching}

The embedded system product development needs the developer to have the strong comprehensive theory knowledge and the practical ability. According to the actual engineering needs of the enterprise, in view of the characteristics of the level of students ' professional knowledge, we classify the experiment items according to the difficulty: basic category, Expansion category and innovation category, see Table 1.

The basic experiment belongs to the verification experiment, which is difficult to meet the basic needs of the training of application development ability. The extended experiment has a certain exploratory nature, which can meet the requirements of students ' main development ability. The innovation experiment content mainly comes from the horizontal research project of the teacher, the 
student uses the extracurricular time, the teacher mainly guides the student to study the related knowledge point, the establishment project team carries on the development practice exploration and the discussion, the teacher only gives the necessary instruction.

Table 1. Embedded Practice Project Layering Schedule

\begin{tabular}{|c|c|c|}
\hline Experimental Type & Experiment Items & Organizational Management \\
\hline Comprehensive Experiment & $\begin{array}{l}\text { Embedded System Kernel Porting } \\
\text { Task Scheduling Management } \\
\text { LCD driver and Touch screen reading } \\
\text { Integrated Embedded Application } \\
\text { Intelligent MP3 Player Design } \\
\text { Portable Oscilloscope Design } \\
\text { Simple Mobile Phone Development }\end{array}$ & $\begin{array}{l}\text { Through the embedded system } \\
\text { development project. }\end{array}$ \\
\hline Development Experiment & $\begin{array}{l}\text { BSP and Hardware Driver } \\
\text { Embedded File system } \\
\text { Embedded File system }\end{array}$ & $\begin{array}{c}\text { Through extracurricular learning } \\
\text { interest groups }\end{array}$ \\
\hline Basic Experiment & $\begin{array}{c}\text { MDK Establishment } \\
\text { Fundamentals of microprocessor } \\
\text { Underlying application foundation } \\
\text { Underlying hardware drivers }\end{array}$ & $\begin{array}{l}\text { Through the in-class learning } \\
\text { group }\end{array}$ \\
\hline
\end{tabular}

\subsection{Establishing extra-curricular open laboratory}

The extracurricular opening laboratory makes up for the insufficiency of the practice class in the class, enables the student to contact the embedded development equipment more and carries on the exploratory study, has effectively raised the student engineering practice and the product development ability, specially must complete the embedded curriculum synthesis design and the graduation design senior student.

\section{Conclusion}

"Embedded System" course is a combination of theory and practice, paying special attention to the cultivation of students ' practical ability, so the CDIO Engineering education model provides a new way of education for the embedded system curriculum. Taking the CDIO Engineering education model as the guiding ideology, in view of the existing problems in the teaching, we have discussed the curriculum system, the choice of experiment platform, the construction of non-standard textbooks and the project-driven teaching mode of layered engineering practice. The practice proves that the reform of CDIO teaching model can effectively improve students ' comprehensive quality and innovative spirit of embedded product development.

\section{Acknowledgments}

This research is one of the periodical achievements of the 18th batch of educational reform projects of Jinan University, "the innovation and practice of the project driving teaching method in the embedded system curriculum" (JG2016022).

\section{References}

[1] WANG Shuowang, HONG Chengwen, CDIO: the Classic Mode of Engineering Education in MIT---An Unscrambling on the CDIO Syllabus. Journal of Higher Education in Science \& Technology, Vol. 28(4), pp. 116-119, 2009.

[2] Zhang Wenfen, Gao ShouPing, Lu Wukui, Teaching Reform and Practice for Embedded System Course in Application-oriented Colleges. China Educational Technology \& Equipment, Vol. 204(18), pp. 39-40, 2010. 
[3] CHEN Chunlin, ZHU Zhangqing, Reform in Engineering Education Based on the Concept of CDIO Education. Education and Modernization, Vol. 94(1), pp. 30-33, 2010.

[4] LI Jianqiang, WANG Zhiqiang, XUE Li-ping, Research of Embedded System Teaching Based on CDIO Mode. Computer Education, Vol.12, pp. 122-123, 2010. 